Jurnal IImiah Farmasi Vol. 11 No. 1 Tahun 2015

\title{
EVALUASI SIFAT FISIK DAN UJI IRITASI SEDIAAN SALEP MINYAK ATSIRI BUNGA CENGKEH DALAM BASIS LARUT AIR
}

\author{
Diah Pratimasari ${ }^{1,}$ Nining Sugihartini ${ }^{2}$, Tedjo Yuwono $^{2}$ \\ ${ }^{1}$ Mahasiswa Program Pasca Sarjana Farmasi, Universitas Ahmad Dahlan, Yogyakarta, Indonesia \\ ${ }^{2}$ Fakultas Farmasi, Universitas Ahmad Dahlan, Yogyakarta, Indonesia \\ Email : nining.sugihartini@pharm.uad.ac.id
}

\begin{abstract}
ABSTRAK
Minyak atsiri bunga cengkeh (Syzygium aromaticum) (MABC) dengan kandungan bahan aktif terutama eugenol telah banyak diteliti berkhasiat sebagai antiinflamasi sehingga penelitian lanjutan terkait formulasinya perlu dilakukan. Formula yang dikembangkan pada penelitian ini adalah bentuk sediaan topikal yaitu salep dengan menggunakan basis larut air. Penelitian ini bertujuan untuk melihat sifat fisik dari sediaan salep larut air dari MABC dan evaluasi terhadap sifat iritatifnya pada berbagai konsentrasi. Sediaan salep basis larut air MABC dibuat dengan menggunakan pencampuran antara PEG 400 dan PEG 4000 dengan metode peleburan. Salep dibuat dengan beberapa konsentrasi MABC yaitu $5 \%$, $10 \%$ dan $15 \%$. Salep dengan masing-masing konsentrasi dievaluasi sifat fisiknya berdasarkan parameter $\mathrm{pH}$, daya sebar dan daya lekat. Salep yang telah diuji sifat fisiknya dievaluasi iritasinya terhadap kulit dengan menggunakan hewan uji marmut dengan metode Draize test. Data yang diperoleh dari percobaan kemudian dianalisis secara statistik dengan ANOVA menggunakan uji$\mathrm{T}$ taraf kepercayaan $95 \%$. Hasil penelitian menunjukkan bahwa sifat fisik salep basis larut air dengan konsentrasi MABC 5\%, 10\% dan 15\% memenuhi persyaratan parameter $\mathrm{pH}$ dan daya lekat. Sedangkan untuk daya sebar ketiga konsentrasi salep menunjukkan hasil yang kurang dari persyaratan yang ditentukan. Analisa statistik terhadap masing-masing percobaan tidak menunjukkan adanya perbedaan yang signifikan. Hasil percobaan terhadap uji iritasi menunjukkan bahwa salep basis larut air konsentrasi 5\%, 10\% dan $15 \%$ tidak menimbulkan iritasi pada kulit marmut.
\end{abstract}

Kata kunci : minyak atsiri bunga cengkeh, salep basis larut air, uji iritasi,Draize test.

\section{ABSTRACT}

Essential oil of clove (Syzygium aromaticum) (MABC) with eugenol as its main active ingredient, has been studied as antiinflammatory agent. Its important to develop formulation in an advanced research. This study has been conducted to develop a topical dosage form (an ointment using a water-soluble base). The physical properties of water-soluble ointment preparation of $M A B C$ and the irritation properties at various concentrations of $M A B C$ have been evaluated. Ointment preparation $M A B C$ water-soluble base created using the mixing of the PEG 400 and PEG 4000 by a fusion method. Ointment made with a various concentration of MABC (5\%, $10 \%$ and 15\%). Ointment with each concentration were evaluated based on its physical properties such as $\mathrm{pH}$, dispersiveness and adhesion. Ointment also tested its irritative properties on the skin, using test animals guinea pigs by Draize test method. Data from those experiments analyzed by ANOVA with T-test level of $95 \%$. The results showed that the physical properties of watersoluble ointment base with MABC concentration of $5 \%, 10 \%$ and $15 \%$ reach the requirements of the $\mathrm{pH}$ and adhesion parameter, but not for its dispersiveness. Statistical analysis of each trial did not show any significant in difference. The experimental results against irritation test showed that the water-soluble ointment base concentration of 5\%, 10\% and $15 \%$ did not cause irritation to the skin of guinea pigs.

Keywords: clove essential oil, water-soluble ointment base, irritation test, Draize test 


\section{PENDAHULUAN}

Eugenol yang terdapat dalam minyak atsiri bunga cengkeh (Syzygium aromaticum) (MABC) telah terbukti memiliki aktivitas yang baik sebagai anti-inflamasi (Kamatou dkk., 2012, Murakami dkk., 2005 dan da Silveirae dkk., 2014), analgesik dan juga antiseptik (Rapp, 2007). Manfaatmanfaat tersebut memacu dikembangkannya MABC dalam bentuk sediaan yang farmasetis dan lebih praktis.

Secara tradisional MABC sering digunakan dengan mengaplikasikannya pada permukaan kulit. Oleh karena itulah pada penelitian ini dikembangkan bentuk sediaan topikal dalam bentuk sediaan yang lebih farmasetis dan lebih praktis. Sediaan topikal yang dipilih adalah bentuk sediaan salep dengan basis larut air. Hal ini dikarenakan basis larut air tidak mengandung bahan yang berlemak sehingga dapat memberikan kenyamanan saat digunakan. Selain itu dengan basis larut air diharapkan pelepasan obat dari sediaannya lebih cepat.

Pada sediaan topikal, salah satu parameter yang penting untuk diperhatikan adalah adanya kemungkinan produk yang diaplikasikan menimbulkan iritasi terhadap kulit. Iritasi merupakan salah satu reaksi buruk yang terjadi pada kulit, yang dapat disebabkan oleh beragam faktor diantaranya lama pemberian, luas area pemberian, tingkat penetrasi dan ketoksikan dari bahan yang diaplikasikan (More, 2013). Munculnya iritasi dapat terjadi setelah beberapa waktu dari pengaplikasian sediaan, ditandai dengan beberapa gejala seperti kulit akan mengering terasa nyeri, mengalami perdarahan, dan pecah-pecah. Iritasi yang terjadi pada kulit ditandai dengan adanya eritema dan edema, dimana eritema atau kemerahan terjadi karena dilatasi pembuluh darah pada daerah yang teriritasi, sedangkan pada udema terjadi perbesaran plasma yang membeku pada daerah yang terluka (Irsan dkk., 2013).

Berdasarkan latar belakang tersebut, maka penelitian ini dilakukan untuk mengetahui sifat fisik dari sediaan salep minyak atsiri bunga cengkeh (Syzygium aromaticum) dan efek iritasinya.

\section{METODE PENELITIAN}

\section{Desain penelitian}

Penelitian ini merupakan penelitian eksperimental dengan menggunakan rancangan penelitian pre dan post test control group design.

\section{Alat dan bahan Penelitian}

Bahan yang digunakan dalam penelitian ini adalah minyak atsiri bunga cengkeh yang didapat dari Pusat Studi Minyak Atsiri / Center of Essential Oils Studies (CEOS) Universitas Islam Indonesia, PEG 4000 dan PEG 400. Peralatan yang digunakan adalah seperangkat alat glass, waterbath, timbangan analitik, alat uji daya menyebar, dan alat uji daya lekat.

\section{Formulasi salep larut air minyak atsiri bunga cengkeh}

Formulasi minyak atsiri bunga cengkeh mengacu ke hasil penelitian Faradiba yang disajikan pada tabel I. Pada masing-masing formula tersebut divariasi konsentrasi minyak atsiri bunga cengkeh sebesar $5 \%, 10 \%$ dan $15 \%$ 
Tabel 1. Formulasi sediaan salep basis larut air minyak atsiri bunga cengkeh

\begin{tabular}{cccc}
\hline Bahan & $\begin{array}{c}\mathrm{F} 1 \\
(\%)\end{array}$ & $\begin{array}{c}\text { F2 } \\
(\%)\end{array}$ & $\begin{array}{c}\text { F3 } \\
(\%)\end{array}$ \\
\hline $\begin{array}{c}\text { Konsentrasi } \\
\text { minyak }\end{array}$ & 5 & 10 & 15 \\
cengkeh & & & \\
PEG 4000 & 66,5 & 63 & 59,5 \\
PEG 400 & 28,5 & 27 & 25,5 \\
\hline
\end{tabular}

Salep dibuat dengan memanaskan PEG 4000 dan PEG 400 kemudian diaduk sampai terbentuk massa yang kental dan homogen dan didinginkan. Minyak atsiri ditambahkan kemudian dicampur hingga homogen (Anief, 1997)

\section{Evaluasi Sifat Fisik Salep Basis Larut Air Minyak Atsiri Bunga Cengkeh}

\section{Uji Daya Sebar}

Sebanyak 0,5 gr salep diletakkan diatas kaca bulat yang berdiameter $15 \mathrm{~cm}$, kaca lainnya diletakkan diatasnya dan dibiarkan selama 1 menit. Diameter sebar salep diukur. Setelahnya, 100 gr beban ditambahkan dan didiamkan selama 1 menit lalu diukur diameter yang konstan (Astuti dkk., 2010).

\section{Uji Daya Lekat}

Sebanyak 0,25 gram salep diletakkan di atas gelas obyek yang telah ditentukan luasnya. Gelas obyek yang lain diletakkan di atas salep tersebut. Setelah itu ditambahkan, beban $1 \mathrm{~kg}$ selama 5 menit pada gelas obyek dan dipasang pada alat tes. Beban seberat 80 gram dilepaskan, dicatat waktunya hingga kedua gelas obyek tersebut terlepas. Percobaan diulangi sebanyak 5 kali (Rahmawati dkk, 2010).

\section{3. $\mathrm{Uji} \mathrm{pH}$}

Sebanyak 0,5 g salep diencerkan dengan $5 \mathrm{ml}$ aquades, kemudian di cek $\mathrm{pH}$ larutannya (Naibaho dkk., 2013).

\section{Evaluasi daya iritasi salep basis larut air minyak atsiri bunga cengkeh}

Uji iritasi sediaan selep basis larut air dilakukan terhadap hewan uji marmot dengan menggunakan metode Draize (1959). Penelitian ini menggunakan 6 ekor marmot berumur rata-rata 2 bulan dan berat badan rata-rata $500 \mathrm{~g}$. Rambut marmot dicukur pada bagian punggungnya sampai bersih. Untuk menghilangkan bulu halus digunakan veet sebagai perontok bulu-bulu halus. Pencukuran dilakukan secara hati-hati agar tidak melukai punggung marmut. Punggung marmut dibagi menjadi 6 bagian yang berbentuk bujur sangkar. Yang akan diberikan perlakuan sediaan salep dengan konsentrasi $5 \%, 10 \%, 15 \%$, basis, kontrol sakit dan kontrol sehat.

Masing-masing sampel iritan sebanyak 0,5 gram dioleskan pada bagian punggung kelinci yang telah dicukur, lalu ditutup dengan kasa steril kemudian direkatkan dengan plester. Setelah 24 jam, plester dan perban dibuka dan dibiarkan selama 1 jam, lalu diamati. Setelah diamati, bagian tersebut ditutup kembali dengan plester yang sama dan dilakukan pengamatan kembali setelah 72 jam (Irsan dkk, 2013). Selanjutnya untuk setiap keadaan kulit diberi nilai sebagai berikut (Draize, 1959):
1. Eritema
a. Tidak ada eritema $=0$
b. Eritema sangat ringan $=1$
c. Eritema ringan $=2$
d. Eritema sedang = 3
e. Eritema berat $\quad=4$ 


\section{Edema}

a. Tidak ada edema $=0$

b. Edema sangat ringan $=1$

c. Edema ringan $\quad=2$

d. Edema sedang = 3

e. Edema berat $\quad=4$

Indeks iritasi dihitung dengan cara menjumlahkan nilai dari setiap kelinci percobaan setelah 24 jam dan 72 jam pemberiaan sampel iritan, kemudian dibagi 4 . Penilaian iritasinya sebagai berikut:

$0,00=$ Tidak mengiritasi

$0,04-0,99=$ Sedikit mengiritasi

$1,00-2,99=$ Iritasi ringan

$3,00-5,99=$ Iritasi sedang

$6,00-8,00=$ Iritasi berat

\section{HASIL DAN PEMBAHASAN}

Salep dengan basis larut air dipilih pada penelitian ini dikarenakan salep basis larut air memiliki beberapa kelebihan seperti mudah dicuci, daya lekat yang baik dan nyaman saat digunakan (Anief,1997). Pada sediaan salep, beberapa evaluasi dilakukan untuk melihat kualitas fisik dari sediaan. Pada penelitian ini pengujian sifat fisik yang dilakukan adalah uji daya sebar, daya lekat dan $\mathrm{pH}$.

Uji daya sebar pada salep dilakukan untuk melihat kemampuan sediaan menyebar pada kulit, dimana suatu basis salep sebaiknya memiliki daya sebar yang baik untuk menjamin pemberian bahan obat yang memuaskan (Naibaho dkk., 2013). Syarat daya sebar untuk sediaan topikal adalah sekitar 5- $7 \mathrm{~cm}$ (Ulaen dkk., 2012), namun pada penelitian ini daya sebar yang didapatkan di bawah dari syarat yang ditentukan (Gambar.1) dengan perbedaan yang tidak signifikan antar masing hasil pengujian ( $p>0.05$ ). Hal ini dapat dikarenakan konsistensi dari salep yang bermassa sehingga mengakibatkan penyebaran tidak terlalu maksimal. Meskipun demikian, semakin tinggi konsentrasi minyak atsiri dalam sediaan salep menunjukkan peningkatan daya sebar dari salep.

Pengujian daya lekat dimaksudkan untuk melihat berapa lama kemampuan salep untuk melekat. Hasil pengujian daya lekat (Gambar.2) menunjukkan bahwa daya lekat dari salep lebih dari 30 menit pada semua konsentrasi. Syarat untuk daya lekat pada sediaan topikal adalah tidak kurang dari 4 detik (Ulaen dkk., 2012). Hal ini menunjukkan sediaan salep basis larut air dengan berbagai konsentrasi minyak atsiri memenuhi persyaratan daya lekat. Hasil uji daya sebar dan daya lekat ini sesuai dengan hasil penelitian sebelumnya yang juga menunjukkan bahwa formulasi minyak atsiri bunga cengkeh dalam emulgel memberikan daya lekat lebih dari 30 menit. Selain itu dengan peningkatan konsentrasi Meningkatkan daya sebar sediaan (Sari dkk., 2015).

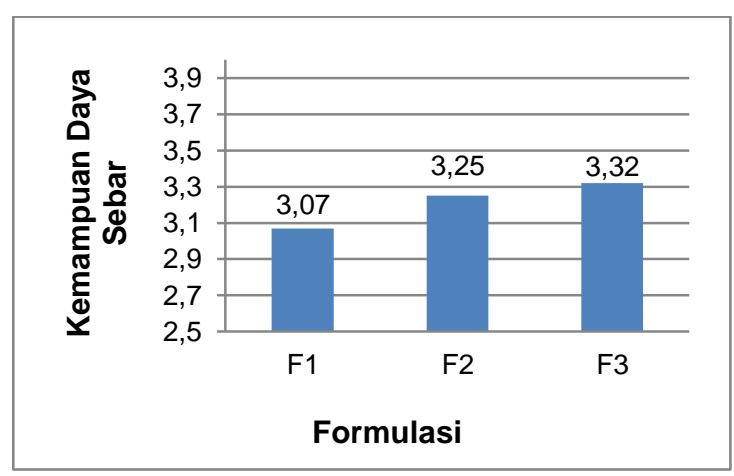

Gambar 1. Grafik Hubungan antara konsentrasi minyak atsiri bunga cengkeh pada salep basis larut air dengan daya sebar. Konsentrasi salep adalah 5\% (F1), 10\% (F2), $15 \%$ (F3) 


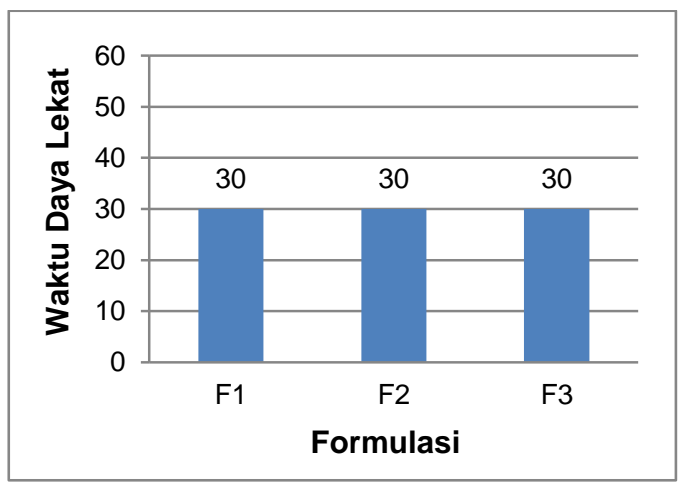

Gambar 2. Grafik Hubungan antara konsentrasi minyak atsiri bunga cengkeh pada salep basis larut air dengan daya lekat. Konsentrasi salep adalah 5\% (F1), 10\% (F2), $15 \%(F 3)$

Pengujian lain yang dilakukan adalah pengujian $\mathrm{pH}$. Pengujian terhadap $\mathrm{pH}$ dimaksudkan untuk melihat tingkat keasaman sediaan untuk menjamin sediaan tidak menyebabkan iritasi pada kulit (Mappa dkk.,2013). Hasil pengujian pH sediaan salep basis larut air minyak atsiri bunga cengkeh berada di antara $\mathrm{pH} 5,84$ - 5,96. Hal ini sesuai dengan yang diharapkan, yaitu $\mathrm{pH}$ berada pada rentang $\mathrm{pH}$ normal kulit yaitu antara 4.5 -7 (Swastika dkk., 2013). Hasil dari pengujian tidak menunjukkan perbedaan yang signifikan antar pengujian ( $p>0,05)$. Sediaan topikal diharapkan memiliki $\mathrm{pH}$ yang berada pada $\mathrm{pH}$ kulit normal dikarenakan jika $\mathrm{pH}$ terlalu basa akan mengakibatkan kulit bersisik, sedangkan jika kulit terlalu asam dapat memicu terjadinya iritasi kulit (Swastika dkk., 2013).

Pengamatan terhadap iritasi yang terjadi pada hewan uji marmut dilakukan terhadap sediaan salep basis larut air dengan 3 macam konsentrasi yaitu 5\%, 10\% dan 15\% ,kontrol basis, dan kontrol sakit menggunakan croton oil. Pengamatan dilakukan dengan menggunakan metode Draize dan diamati terhadap eritema dan udema yang terjadi pada kulit marmut. Setelah di hitung skoring eritema dan udema yang terjadi kemudian dihitung indeks iritasinya.

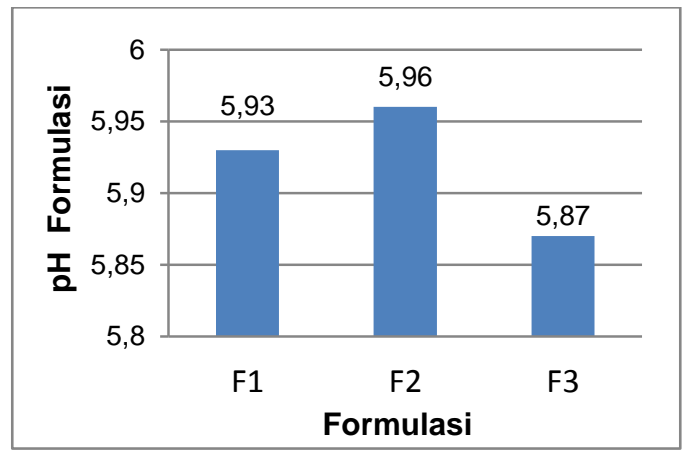

Gambar 3. Grafik Hubungan antara konsentrasi minyak atsiri bunga cengkeh pada salep basis larut air dengan $\mathrm{pH}$. Konsentrasi salep adalah 5\% (F1), 10\% (F2), 15\% (F3)

Hasil indeks iritasi dari kontrol sehat, kontrol basis, dan sediaan salep basis larut air minyak atsiri bunga cengkeh pada F1, F2, dan F3 adalah tidak mengiritasi, sedangkan pada kontrol sakit terjadi iritasi ringan (Tabel II dan Tabel III).

Tabel 2. Hasil Perhitungan Indeks Iritasi

\begin{tabular}{lc}
\hline \multicolumn{1}{c}{ Kelompok Uji } & Indeks Iritasi \\
\hline Tanpa & 0 \\
Pemberian & \\
\hline Croton Oil & 1,8 \\
Basis & 0 \\
Formula 1 (5\%) & 0 \\
Formula 2 (10\%) & 0 \\
Formula 3 (15\%) & 0 \\
\hline
\end{tabular}


Tabel 3. Hasil Pengamatan Uji Iritasi

\begin{tabular}{ccccc}
\hline \multirow{2}{*}{ Kelompok Uji } & \multicolumn{3}{c}{ Waktu Pengamatan } \\
\cline { 2 - 5 } & \multicolumn{2}{c}{ 24 jam } & \multicolumn{2}{c}{ 72jam } \\
\cline { 2 - 5 } & Eritema & Udema & Eritema & Udema \\
\hline $\begin{array}{c}\text { Rata-rata } \\
\text { Tanpa } \\
\text { Pemberian }\end{array}$ & 0 & 0 & 0 & 0 \\
$\begin{array}{c}\text { Rata-rata } \\
\text { Croton Oil }\end{array}$ & 2,4 & 0,8 & 3 & 1 \\
$\begin{array}{c}\text { Rata-rata } \\
\text { Basis }\end{array}$ & 0 & 0 & 0 & 0 \\
$\begin{array}{c}\text { Rata-rata } \\
\text { Formula 1 } \\
\text { (5\%.) }\end{array}$ & 0 & 0 & 0 & 0 \\
$\begin{array}{c}\text { Rata-rata } \\
\text { Formula 2 } \\
\text { (10\%.) }\end{array}$ & 0 & 0 & 0 & 0 \\
$\begin{array}{c}\text { Rata-rata } \\
\text { Formula 3 } \\
\text { (15\%.) }\end{array}$ & 0 & 0 & 0 & 0 \\
\hline & & & & \\
\hline
\end{tabular}

\section{KESIMPULAN}

Sifat fisik sediaan salep MABC yang meliputi daya sebar, daya lekat dan $\mathrm{pH}$ tidak memiliki perbedaan yang signifikan antar masing-masing formula. Sediaan salep MABC tidak memiliki efek iritasi pada dosis 5\%,10\% da $15 \%$ pada hewan uji marmut dengan metode Draize.

\section{DAFTAR PUSTAKA}

Anief, M. 1997. Ilmu Meracik Obat. GajahMada University Press, Yogyakarta.

Astuti I. Y., D. Hartanti, dan A. Aminiati.2010. Peningkatan Aktivitas Antijamur Candida albicans Salep Minyak Atsiri Daun Sirih (Piperbettle LINN.) melalui Pembentukan Kompleks Inklusi dengan $\beta$-siklodekstrin. Majalah Obat Tradisional. 15: 94-99.
Da Silveira e Sá, R., Andrade, L.N., de Oliveira, R.R.B., and de Sousa, D.P., 2014, A Review on AntiInflammatory Activity of Phenylpropanoids Found in Essential Oils, Molecules, 19:14591480.

Draize, J.H. 1959. Dermal Toxicity. The Association of Food and Drug Officials of the United States, Bureau of Food and Drugs, Austin, TX. pp. 46-49. Available as PDF file

Irsan,M.A, Manggav, E., Pakki., Usmar., 2013, Uji Iritasi Krim Antioksidan Ekstrak Biji Lengkeng (Euphoria longana Stend) pada Kulit Kelinci (Oryctolagus cuniculus), Majalah Farmasi dan Farmakologi,17(2):5560.

Kamatou, G.K., Vermaak, I., and Viljoen, A.M., 2012, Eugenol-From the Remote Maluku Islands to the International Market Place: A Review of a Remarkable and Versatile Molecule, Molecules, 17:6953-6981.

Mappa, T.,Edi,J,H \& Kojong, M.,2013, Formulasi Gel Ekstrak Daun Sasaladahan (Pperomia pellucida L.) dan Uji Efektivitasnya terhadap Luka Bakar pada Kelinci, Jurnal IImiah Farmasi, 2(20), 49-56.

More, BH., Sakhawarde, SN., Tembhurne, SV., Sakarkar, DM., 2013, Evaluation for Skin Irritancy Testing of Developed Formulations Containing Extract of Butea Monospermafor Its Topical Application, International Journal of Toxicology and Applied Pharmacology, 3(1) : 10-13.

Murakami, Y., Shoji, M., Hanazawa, S., Tanaka, S., and Fujisawa, S., 2003. Preventive effect of bis-eugenol, a eugenol ortho dimer, on lipopolysaccharide-stimulated nuclear factor kappaB activation and inflammatory cytokine expression in macrophages, Biochem. Pharmacol., 66:10611066.

Naibaho, D.H., Yamkan, V,Y., Weni, Wiyono., 2013. Pengaruh Basis Salep Terhadap Formulasi Sediaan Salep Ekstrak Daun Kemangi (Ocinum sanchum L.) pada Kulit Punggung 
Kelinci yang dibuat Infeksi Staphylococcus aureus, Jurnal ilmiah Farmasi - UNSRAT, Vol.2 N0.02.

Rahmawati, D., Sukmawati, A. \& Indrayudha, P., 2010, Formulasi Krim Minyak Atsiri Rimpang Temu Giring (Curcuma heyneana Val \& Zijp): Uji Sifat Fisik dan Daya Antijamur Terhadap Candida albicans Secara In Vitro, Majalah Obat Tradisional, 15 (2), 56-63.

Rapp, C., 2007, Clove oil as effective as topical anesthetic. Herbal Gram, hal 26.

Sari, D.K., Sugihartini, N., Yuwono,T., 2015, Evaluasi Uji Iritasi dan Uji Sifat Fisik Sediaan Emulgel Minyak Atsiri Bunga Cengkeh (Syziqium aromaticum), Pharmaqiana, 5(2) : 115-120.

Swastika, A, Mufrod \& Purwanto., 2013, Aktivitas Antioksidan Krim Ekstrak Sari Tomat (Solanum lycopersicum L.), Trad Med Journal, 18(3),132-140.

Ulaen, Selfie P.J., Banne, Yos Suatan \& Ririn A., 2012, Pembuatan Salep Anti Jerawat dari Ekstrak Rimpang Temulawak (Curcuma xanthorrhiza Roxb.), Jurnal IImiah Farmasi, 3(2), 45-49. 